\title{
Study on the Development Status, Risk Problems and Countermeasures of Internet Consumer Finance in China
}

\author{
$\mathrm{Dan} \mathrm{Hu}$
}

School of Finance and Economics Management, Sichuan University of Arts and Science, Da Zhou, SiChuan, China *Corresponding author. Email: 184403206@qq.com

\begin{abstract}
With the continuous development of science and technology and the continuous improvement of the financial market, Internet consumer finance has attracted many users resulting in its obvious advantages of convenience, quickness and wide coverage, which has greatly enriched the types of Internet financial services and improved the quality of Internet financial services in China. However, with the rapid development of Internet consumer finance, the credit risk, fraud risk, technical risk, operational risk, market risk and other risks of Internet consumer finance need to be paid special attention. In this work, based on the introduction of the development status of the Internet consumer finance market in China for economic information management, this paper makes a comprehensive analysis of the risks existing, and puts forward effective countermeasures for various Internet consumer finance risks.
\end{abstract}

Keywords: Internet consumer finance; Economic information management; Risk; Credit reporting; Countermeasure.

\section{INTRODUCTION}

China's Internet consumer finance started late and developed rapidly. It was not until 2013 that China's internet finance entered a rapid development stage. In recent years, various Internet consumer financial platforms have sprung up in the financial market, such as "Ant Credit Pay" under Alibaba and "JD Baitiao" under JD Finance, etc. These platforms have won the consumers' trust with their features of wide coverage and convenient use. With the constant change of people's consumption concept and the improvement of their life quality, the development of China's Internet consumer finance has been further promoted, which produced many long-tailed customer groups, greatly expanding the coverage of Internet financial services[1-3]. However, with the growth of Internet consumer finance, there are some problems that can't be ignored.

\section{DEVELOPMENT STATUS OF INTERNET CONSUMER FinANCE IN ChINA}

\subsection{There are Many Participants with Different Endowments}

For the past few years in China, with the fastgrowing Internet consumer finance market, the scale of participants is expanding which includes, not only consumer finance companies but also traditional commercial banks. By upgrading and optimizing traditional financial products, they have launched a series of Internet financial products and services. In addition, there are some e-commerce platforms introducing various types of consumer financial services with their powerful consumption scenarios, data advantages, and their relatively complete industrial ecological chains to cater to the personal consumption needs of current consumers. There are also some emerging Internet consumer finance platform, for example, the P2P lending platforms which serve vertical fields or segmented consumers. Generally speaking, the existing Internet consumer finance platforms can be divided into two systems: banking system and non-banking system. However, with the difference of 
customer's acquisition capability, service level and risk management, the advantages of Internet consumer financial platforms are also different. At the time of the Internet financial consumer platforms boom, consequential undesirable phenomena appear frequently, which makes people turn pale at the mention of Internet lending. But with the continuous adjustment and improvement of relevant regulatory policies, the development of the Internet consumer finance market is becoming more and more perfect[3-4].

\subsection{The Speed and Scale of the Development is in Rapid Growth}

Internet consumer finance emerges with economic and social development and the change of people's consumption concept. Its development is influenced by many factors, such as macro-economic growth and per capita disposable income increase, which have laid a foundation for the development of Internet consumer finance and become its fundamental driving force. Besides, with the constant development of science and technology, successive breakthroughs in Internet technology and the continuous integration of advanced technologies such as big data and cloud computing, it provides a solid technical support for the development of Internet consumer finance. At the same time, the upgrading of people's consumption concept and the transformation of consumption patterns has also strongly promoted the development of Internet consumer finance. Compared with developed economies, China's Internet consumer finance development has a relatively late start, but its momentum is great, its speed is rapid, and its scale is constantly expanding[5]. Data show that in just a few years, the scale of Internet consumer credit in China has increased from 18.7 billion yuan in 2014 to 16.3 trillion yuan in 2019.

\subsection{Diversification of Consumption Scenarios and Centrali-zation of Service Objects}

Different from traditional consumer finance, Internet consumer finance relies on the popularization of smart devices and the application of advanced technologies, which makes consumption scenarios more diversified and consumption behaviors more decentralized. Driven by the development momentum of Internet consumer finance, all kinds of consumption scenarios can be realized through Internet consumer finance, such as real consumption and virtual consumption, mortgage, car loan, decoration, shopping and travel, etc., which are closely combined with various consumption scenarios. Moreover, due to the increasing diversification of Internet consumer finance support scenarios, a large number of long-tailed customer groups have been attracted, which has greatly enriched the service types and expanded the service range of Internet consumer finance. However, on the whole, these customers are mainly concentrated in groups not covered by consumer credit of traditional financial institutions, such as college students and freelancers. These groups are similar in that they all have advanced consumption concepts, have a high acceptance of new things and are familiar with the Internet [6].

\section{AnAlysis on the Performance AND CAUSES OF INTERNET FinANCIAL RISKS}

\subsection{Credit Risk}

Credit risk refers to the discreditable behaviors of the borrowers who fail to repay the arrears in accordance with the agreement due to some subjective or objective reasons which mainly manifest as failing to return the loan as agreed, using false materials to make loans, and illegally swindling credit card amount. The main causes of credit risk are as follows: Firstly, an unified national credit reporting system has not been established and the coverage of the People's Bank of China's credit reporting system is relatively limited. At present, most financial credit reporting systems have not yet been connected with the People's Bank of China's, making it difficult for financial platforms to share and integrate users' credit information. Secondly, the intangibility and virtuality of Internet consumer finance have opened a convenient door for consumers to fabricate false information and conceal records of dishonesty, which makes it arduous for Internet consumer financial platforms to effectively evaluate users' credit. Meanwhile, compared with the high-net-worth customers of traditional consumer finance, Internet consumer finance is mostly long-tailed customers, whose repayment ability is relatively low, and it is prone to default. Furthermore, most loan forms of Internet consumer finance need no guarantee or collateral and their binding force is far lower than that of traditional consumer finance. Lastly, some Internet consumer finance users have relatively weak credit awareness, lack of contract spirit, and have not yet formed a good credit environment of honesty and trustworthiness.

\subsection{Fraud Risk}

Fraud risk mainly refers to the fact that Internet consumer financial institutions deliberately exaggerate their profitability and their own strength so as to induce consumers to apply for high loans and obtain personal information of consumers to make illegal profits, such as trap loans and campus loans. In recent years, fraudulent credit incidents have been repeatedly exposed in the financial market and the main causes of them comprise: First, with the increasingly fierce competition in the Internet consumer financial market, some Internet consumer financial institutions have 
lowered the auditing standards for loan applicants in order to enhance market competitiveness, resulting in users exceeding credit loans without knowing it. Second, some young consumers lack knowledge about credit and finance and are short of law consciousness and risk prevention ability, which makes them extremely vulnerable to deception and induction by illegal Internet consumer financial platforms, giving rise to damage to their legitimate rights and interests. Third, because of limited experience, it is intractable for young consumers to judge and identify the potential risks of Internet consumer finance. Therefore, they are the primary targets of deception and inducement of illegal Internet consumer financial institutions and platforms. Fourth, some consumers want to apply for loans as soon as possible because of blind consumption or urgent need of funds, which paves the way for fraud by platforms or institutions.

\subsection{Technical Risk}

With the continuous breakthrough of Internet technology and the rapid development of the financial market, the emergence and development of Internet consumer finance is accelerating. But at the same time, a new round of financial technology risks has also been produced, including the spread of Trojan Horse, communication network terminals, system software failures, system hardware faults, hacker attacks, etc. As a result, the information system can't effectively serve the users, resulting in varying degrees of profit losses. In Internet consumer financial services, the technical risk mainly shows as communication interruption, loopholes or failures in platform terminals which affect the normal operation of transactions and threaten the security of users' information, thus harming the interests of users. There are two main reasons for the technical risk of Internet consumer finance. First, communication, power supply and other infrastructure have failed due to force majeure, which makes it more difficult to meet users' demand for high-quality and high-speed mobile networks. Second, some Internet consumer finance platforms lack awareness of network security and the maintenance, updating and renovation of the platform systems, software and vulnerabilities are not in time and far from satisfactory, which give readily exploitable loopholes for criminals to attack and virus to invade.

\subsection{Operational Risk}

Mobile terminals can operate a series of services of Internet consumer finance, including credit application, loan settlement application, Internet payment, etc. Statistics show that more than $27 \%$ of users' legitimate rights and interests have been damaged due to improper operation. Operational risk is often caused by the following two factors: One is that users are unfamiliar with or careless with the Internet financial platform system, resulting in operational errors and hence loss of benefits, such as misunderstand the loan application process, mistaking the loan amount, and losing the platform account password; The other is that platform loopholes or errors can also fail the financial business handling. Consequently, there are three main factors leading to the operational risks: First, the platform lacks a sound internal control mechanism. The scope of internal supervision of the platform still needs to be expanded and the supervision needs to be stepped up. The punishment mechanism is imperfect, which causes the insufficiency of the binding force. There is also a lack of clear responsibility distribution mechanism among different departments, which leads to frequent problems in platform business. Second, the maintenance and inspection of the platform operating system are not in time or effective, and the contingency plans are inadequate. When sudden instance occurs, it is difficult to deal with it in a timely and effective manner, hence resulting in transaction failures or damages to the rights and interests of consumers. Third, the communication mechanism needs improving. The inadequate communication between Internet consumer finance platforms and consumers can lead to inconsistencies in the issuing and execution of transaction orders, which in turn brings about errors in financial business handling.

\subsection{Market Risk}

The Internet consumer financial market is closely related to financial market, currency market and commodity market, and is easily affected by other economic factors such as deposit and loan interest rate, currency exchange rate, stocks and securities. The changes and fluctuations of these factors can trigger most of the market risks of Internet consumer finance, which are mainly manifested as follows: On the one hand, the changes in reserve requirement stipulated by the People's Bank of China and the fluctuations in interest rates of commercial banks have brought tremendous to the financing and reversal of Internet consumer finance; On the other hand, when the stocks, securities, real estate, bulk commodities, exchange rate and other markets fluctuate, it will also have an impact on the stability of Internet consumer financial market to a certain extent.

\section{Countermeasures AND CONTROL AND MANAGEMENT MEASURES FOR THE INTERNET CONSUMER FinANCIAL RISK}

\subsection{Improve Legal Norms and Innovate Supervision Mode}

In the last few years, the financial market of China has exposed many problems on the Internet consumer finance risk, such as forcible debt collection of $\mathrm{P} 2 \mathrm{P}$ lending platforms, college students falling into the trap 
of campus loans, P2P lending platforms running away and so on. In response to the chaos in the field of Internet finance, the State Council has successively issued a series of special rectification plans. In July 2015, the State Council issued the Guiding Opinions on Promoting the Sound Development of Internet Finance (Yinfa [2015] No.221). In March 2016, the People's Bank of China and China Banking Regulatory Commission introduced the Guiding Opinions on Enhancing the Financial Support for New Consumption Areas (Yinfa [2016] No.92). Since then, China has opened a new era of comprehensive supervision of Internet finance. Internet consumer finance has gradually embarked on an orderly and steady development path. However, as the development of Internet consumer finance in China is still in its infancy, it is necessary for relevant legislative departments to further improve relevant laws and regulations and formulate specific implementation rules based on the actual situation of Internet consumer finance at different stages of development, so as to promote the development of Internet consumer finance.

In addition, with a large number of participants in Internet consumer finance and distinctive business scopes, service objects and operation modes, the regulatory authorities are facing higher requirements. They not only need to strengthen functional supervision while striving to implement differentiated supervision, but also need to formulate targeted supervision standards to enhance departmental cooperation and exchanges, provide good development environment for Internet consumer finance and stimulate the vitality and innovation of the Internet financial market. At the same time, the authorities are also supposed to pay close attention to the development of the Internet financial market, timely adjust the regulatory model, optimize the thought of supervision and build a dynamic and multi-party response Internet financial market supervision system. They should not only strictly control, intervene and crack down on illegal behaviors to create a fair and healthy environment for the Internet financial market, but also constantly improve the risk prevention and control ability of the Internet financial market to promote the sound, orderly and steady development of the Internet consumer finance industry.

\subsection{Complement the Credit Reporting System and Protect the Rights and Interests of Consumers}

The sound and stable development of the Internet consumer financial market can't be separated from the support of a professional and legal credit reporting system. Besides, the growing maturity of big data technology provides a steady technical support for the construction of credit reporting system. Internet consumer finance, as an emerging type of finance, requires regulatory authorities to strengthen the collection and analysis of consumer data and credit data of user groups on the basis of the credit reporting system of the People's Bank of China, to further improve the credit reporting system by stepping up cooperation with relevant departments and to establish an all-inclusive punishment mechanism in credit loss, safeguarding the steady development of Internet consumer finance.

Nowadays, the development of Internet consumer finance is in a period of rapid growth. All participants in the market should strengthen cooperation and jointly build and share a credit data platform on the premise of ensuring the authenticity of data. It is necessary to support the development of Internet finance industry associations, consult as widely as possible, improve the credit evaluation system, and enhance the scientific nature of assessment criteria, in an effort to inquire and know about consumers' credit situation and credit qualifications more accurately. Besides, the Internet finance industry associations are also supposed to uphold the principles of legality, compliance and integrity operation, protect the legitimate rights and interests of credit consumers, and promptly remind consumers of the risk of online credit and other possible risks. Finally, a consumer rights protection mechanism needs to be set up to broaden the channels of consumer rights protection. Increasing publicity to popularize the knowledge of finance, credit and credit reporting to consumers and enhance consumers' awareness of rights protection and financial risk prevention ability.

\subsection{Renew the Management Concept and Improve the Industry Associations}

The Internet consumer finance platforms need to learn from the developed countries of their successful experience in construction and development, to establish a multi-party response mechanism and a risk identification and prevention and control mechanism in line with the development characteristics of Internet consumer finance in China so as to enhance the exchange and communication of experience within the industry and build a financial risk prevention mechanism with wide coverage and deep involvement. This requires the Internet consumer finance platforms to introduce advanced risk management concepts and strengthen cooperation with guarantee companies to reduce financial risks and improve the security of platform operations. At the same time, the platform should consciously accept the guidance and supervision of the regulatory authorities and industry associations, operate in compliance and legality, optimize the management model, and implement a refined management model. Furthermore, a risk management team is needed to fully integrate offline financial information in order to continuously supplement and 
improve the network database and enhance the efficiency of asset operations. Lastly, government departments, industry associations, regulatory departments and Internet consumer finance platforms all need to further strengthen communication and cooperation, build a data inquiry and exchange platform, and enhance the industry's risk prevention and control capabilities.

\subsection{Strengthen Talent Allocation and Innovate Supervision Technology}

During the development process of Internet consumer finance, some outstanding problems are gradually exposed which restrict the development quality of the Internet consumer finance industry to a certain extent, for instance, the unbalanced regional distribution of financial talents. In this regard, effective measures should be taken to introduce talents, especially professional financial ones, such as raising salary and equity stimulus. In addition, an Internet financial platform linkage mechanism should be established nationwide to break the spatial barriers for professional financial talents and help the Internet financial industry break through the bottleneck of development. What's more, it is essential to strengthen the assessment and training of employees, increase the training of risk awareness, and consistently improve the professional ability of relevant employees. At the same time, computer professionals, as an indispensable human resource in the development of Internet consumer finance, need to further increase the training and introduction of such talents in order to continuously improve the R\&D and innovation capabilities of the Internet consumer finance platforms, promote the optimization and upgrading of the platforms and enhance the security and stability of the platform system, improving the anti-risk ability of the platforms. Finally, it is important to encourage and support platform employees to learn key technologies, participate in technological innovation and establish an emergency plan mechanism of risk so as to create a safe and reliable internal and external environment for platform operations, minimizing the operational risks of the platform system.

\subsection{Upgrade the Precaution Ability of Consumers and Pr-oactively Safeguard Rights}

To enhance consumers' awareness and capability of risk prevention, it is needed to make full use of the publicity advantages of mass media and increase the publicity channels of Internet consumer finance knowledge as ways to guide consumers to enhance their understanding of Internet consumer finance platforms and their products. At present, traditional media, like TV advertisements, and new media, such as We Chat official account push and Internet platform publicity and reporting, are all important ways to popularize the knowledge of Internet consumer finance. They can effectively help consumers judge and make decisions on Internet consumption services, guide consumers to form correct and healthy consumption concepts, avoid impulsive consumption, conspicuous consumption and blind consumption, and maintain the correct concept of rational consumption and moderate consumption especially for young consumer groups such as college students and white-collar workers, etc. Moreover, consumers themselves should also heighten their awareness of information security and improve their vigilance and prevention ability against Internet consumer financial fraud. In the meantime, it is necessary for consumers to develop good consumption habits, and avoid bad credit records as a result of intentional arrears, overdue payment and other dishonest behaviors. Finally, consumers need to keep a good grip on their legitimate rights and interests, improve their identification capacity, and not blindly buy products or services on the Internet consumer finance platforms. In the process of using the platforms, they need to put much more of a focus on relevant information records and data collecting. When legitimate rights and interests are damaged, they can ask for assistance from relevant departments promptly and safeguard their own rights and interests through legal channels, developing their own ability to deal with financial risks.

\section{CONCLUSION}

With rapid development of Internet consumer finance, the combination of online and offline consumption scenarios is closer. Diversified consumption scenarios not only enrich Internet consumer financial products and improve the quality of Internet consumer financial services, but also increase Internet financial risks to a certain extent. Therefore, we should take measures to strengthen risk management and guide the way of sound development of the Internet finance industry, such as further raising legal norms, perfecting the credit reporting system, updating the platform management concept, strengthening the allocation of talents, improving consumers' risk prevention ability and so on.

\section{REFERENCES}

[1] Q. Liu, Z. Tang, C. Wu, X. Tang, Analysis of problems and countermeasures in the development of internet consumer finance, Financial sight, 2021, pp. 71-73. DOI: https://doi.org/10.19699/j.cnki. issn2096-0298.2021.11.071.

[2] Z. Zhou, P. Zhang, F. Wang, Research on internet consumer finance risk and its prevention and control path, Journal of Qiqihar Un-iversity (Phi \& Soc Sci), 2020, pp. 63-67. DOI: 
https://doi.org/10.13971/j.cnki.cn23-1435/c.2020.1 0.017 .

[3] Q. Wang, Risk prevention of internet consumption finance from the perspective of financial ethics, Journal of Shenzhen Polytechnic, 2020, pp. 10-15. DOI:

https://doi.org/10.13899/j.cnki.szptxb.2020.04.

002.

[4] G. Gu, W. Zhu, Time-Varying transmission effects of internet finance under economic policy uncertainty and internet consumers' behaviors: evidence from China, Journal of Advanced Computational Intelligence and Intelligent Informatics, 2021, pp. 554-562.

[5] S. An, Analysis on the existing risks and preventive strategies of china's internet consumer finance, Proceedings of 2nd International Symposium on Frontiers of Economics and Management Science, 2021, DOI: 10.26914/c.cnkihy.2021.005835.

[6] H. Wang, Research status of internet consumer finance, Service S-cience and Management, 2019, pp. 199-204, DOI: 10.12677/SSEM.2019.85029. 